\title{
The Frequency and Types of Chromosomal Aberrations in the Patients with Hypogonadism
}

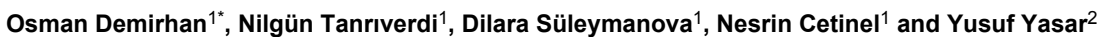

${ }^{1}$ Department of Medical Biology and Genetics, Faculty of Medicine, Çukurova University, Balcalı-Adana/Turkey

${ }^{2}$ Faculty of Medicine, Çukurova University, Balcalı-Adana/Turkey

"Corresponding author: Osman Demirhan, Department of Medical Biology and Genetics, Faculty of Medicine, Çukurova University, 01330 Balcalı-Adana, Turkey, Tel: 90-322-3387140; Fax: 90-322-3386572; E-mail: osdemir@cu.edu.tr

Rec Date: October 30, 2014; Acc Date: December 8, 2014; Pub Date: December 11, 2014

Copyright: ( $) 2015$ Demirhan O, et al. This is an open-access article distributed under the terms of the Creative Commons Attribution License, which permits unrestricted use, distribution, and reproduction in any medium, provided the original author and source are credited.

\begin{abstract}
Objectives: Hypogonadism is the clinical manifestation of the impaired function of the testes and the ovaries, and is either due to endocrinological problems or chromosomal abnornlalities (CA). Chromosomal analysis is one important piece in the hypogonadism individuals, and becomes essential from the clinical point of view.
\end{abstract}

Design: To determine the frequency, types of CAs in a hypogonadism population.

Materials and method: The current study was a retrospective analysis to examine the CAs and prevalence in 64 cases with unexplained hypogonadism problem. The samples were cultured routinely for the karyotype analysis using $\mathrm{G}$ banding.

Results: A total of 64 individuals with infertility was analysed. The karyotype results were normal in $52(81.2 \%)$ of 64 individuals. However, CAs were detected in $12(18.8 \%)$ of all individuals. The $15.6 \%$ of these CAs was numerical aberrations, and also structural CA was $3.1 \%$. Specifically, Klinefelter syndrome (KS) was the most common karyotype (14.1\%,9 cases) among the all cases, followed by $46, \mathrm{XX}$, anoploidy; $46, \mathrm{Xi}(\mathrm{Xq})$ and 46,XY,robt $(14 ; 15)$.

Conclusion: We found a high rate CAs $(18.8 \%)$ in patients with hypogonadism. Therefore, cytogenetic analysis can be strongly recommended in hypogonadism individuals, and should be performed routinely in both the male and female with hypogonadism.

Keywords: Hypogonadism; Chromosome abnormalities; Klinefelter syndrome; Isochromosome $\mathrm{Xq}$

\section{Introduction}

Hypogonadism is a medical term which describes a diminished functional activity of the gonads - the testes and ovaries in males and females, respectively. Certain patients have hypogonadism from birth, while others may develop the condition later in their life. The disease has different features in males and in females, before and after the onset of puberty. If onset is in pre-pubertal boys, signs and symptoms of lack of testicular function include a change of male hair distribution, including facial, chest, and axillary hair, poor development of skeletal muscles, and disturbance of bone growth resulting in abnormally long arms and legs. Blood levels of the male hormone testosterone are low. Also observed are missing laryngeal enlargement, failure of vocal chord thickening, and alterations in body fat distribution. When hypogonadism occurs in males after puberty, low concentration of testosterone in the blood causes lack of energy, weakness, lethargy and diminished sexual function, reduced bone mass and often anaemia. In girls with hypogonadism before puberty, impaired ovarian function leads to failure of progression through puberty. The absence of periods is the most common feature. Blood levels of estradiol are low. When hypogonadism occurs after puberty, irregular periods or absence of periods is the usual concern. The patients develop ovarian suppression which manifests as infertility, decreased libido, breast atrophy, and osteoporosis.

For male patients with primary hypogonadism, the most common cause is a genetic disorder, a chromosome abnormality which occurs in one case per approximately 1,000 live births. Primary hypogonadism is more common in boys than in girls because the incidence of Klinefelter syndrome (KS) is higher than the incidence of the equivalent condition for girls, Turner syndrome (TS) [1]. Hypogonadotrophic hypogonadism $(\mathrm{HH})$ in men occurs more rarely. It is estimated, though, that less than five per cent of men with $\mathrm{HH}$ are diagnosed and are receiving hormone replacement therapy; around a fifth of men aged more than 50 years are believed to have androgen deficiency. For women with primary hypogonadism, the most common cause is a genetic disorder known as TS, a chromosome abnormality which occurs with an incidence of one case per approximately 5.000 live births. The incidence of $\mathrm{HH}$ in females is equal to that in males. Chromosome study in the males and females with hypogonadism becomes essential from the clinical point of view. Little is known, however, about other underlying genetic causes. Therefore, we analysed 50 boys and 14 females seen by the same physician during the childhood or adolescence for hypogonadism. 


\section{Materials and Methods}

The present cases are phenotypically 50 males or 14 females with hypogonadism during the childhood, adolescence and adult. They have the underdeveloped testes, lack of penile enlargement, absence of pubic, auxiliary, facial hair, low levels of testosterone, high-normal to high levels of luteinizing hormone (LH), follicle-stimulating hormone (FSH), loss of libido, erectile dysfunction. All cases born to young healthy, non-consanguinous couple was clinically found to have hypogonadism. IQ was normal. There was no family history of any congenital anomaly. Over the past $15 \mathrm{yr}$ in our laboratory, postnatal karyotyping was done in 64 patients with hypogonadism. The mean age of cases was 17.6 years (range 9-33 years). Patients with hypogonadism who were seen in the out-patient clinics of both the Paediatric and Urology Departments, Faculty of Medicine, Çukurova University. The diagnosis of the patients is made on the basis of a chromosomal analysis in Department of Medical Biology and Genetics, Faculty of Medicine, Çukurova University. Metaphase chromosome preparations from peripheral blood were made according to the standard cytogenetic protocols. Fifty metaphases were analyzed in all the patients, but in cases of abnormalities and mosaicism the study was extended up to 100 metaphases. All CAs were reported according to the current international standard nomenclature (ISCN, 2009).

\section{Results}

A total of 64 individuals with infertility was analysed. Karyotype results were divided into two categories: numerical and structural CAs were shown in Table 1. The karyotype results were normal in $52(81.2 \%)$ of 64 individuals. However, CAs were detected in $18.8 \%$ (12) of all individuals.

\begin{tabular}{|c|c|c|c|c|}
\hline Cytogenetic category & Karyotypes & No. of cases & $\begin{array}{l}\text { Frequency in all cases } \\
(\%)\end{array}$ & Clinical findings \\
\hline Normal & $46, X X$ or $46, X Y$ & 52 & 81.2 & \\
\hline \multirow[t]{2}{*}{ Abnormal } & $\begin{array}{l}\text { Numerical and structural chromosome } \\
\text { abnormalities }\end{array}$ & 12 & 18.8 & \\
\hline & Total & 64 & & \\
\hline \multicolumn{5}{|c|}{ Numerical chromosome abnormalities } \\
\hline Klinefelter syndrome & $47, X X Y$ & 6 & & \multirow{4}{*}{$\begin{array}{l}\text { Prepubertal } \\
\text { underdeveloped testes, lack of penile } \\
\text { enlargement, absence of pubic, auxiliary, } \\
\text { facial hair } \\
\text { Postpubertal } \\
\text { delayed puberty, constitutional delay, } \\
\text { infertility, low levels of testosterone, } \\
\text { high-normal to high levels of LH and } \\
\text { FSH, loss of libido, erectile dysfunction }\end{array}$} \\
\hline $\begin{array}{l}\text { Klinefelter syndrome with } \\
\text { isochromosome }\end{array}$ & $47, X i(X q) Y$ & 2 & & \\
\hline$X$ long arm abnormalities & $46, X Y / 47, X X Y(20 \%)$ & 1 & & \\
\hline \multirow[t]{2}{*}{ Klinefelter syndrome with mosaic } & $46, \mathrm{XX}$, anoploidy (15\%) & 1 & & \\
\hline & Total & 10 & 15.6 & \\
\hline \multirow[t]{2}{*}{$\begin{array}{ll}\text { Structural } & \text { chromosome } \\
\text { abnormalities } & \end{array}$} & $\begin{array}{l}46, X i(X q \\
46, X Y, \operatorname{robt}(14 ; 15)\end{array}$ & $\begin{array}{l}1 \\
1\end{array}$ & & \\
\hline & Total & 2 & 3.1 & \\
\hline
\end{tabular}

Table 1: The frequency and types of chromosomal abnormalities in a hypogonadism population.

The $15.6 \%$ of these CAs was numerical aberrations, and also structural CAs were $3.1 \%$. Specifically, Klinefelter syndrome was the most common karyotypes ( $14.1 \%, 9$ cases) among the all cases, followed by 46,XX,anoploidy (15\%); 46,Xi(Xq) and $46, X Y$,robt $(14 ; 15)$.The incidence of abnormal karyotype was higher in males than females (the male-female ratio=3.0) (Table 1).

\section{Discussion}

The genetic causes of infertility are varied and include CAs, single gene disorders and phenotypes with multifactorial inheritance. The complex organization and regulation of the human hypothalamicpituitary-gonadal axis render it susceptible to dysfunction in the face of a variety of genetic insults, leading to different degrees of $\mathrm{HH}$. Despite the major genetic advances in understanding $\mathrm{HH}$ over the past 20 years, a pathogenic genetic defect can be found in around $30 \%$ of cases, suggesting that many mutations remain to be discovered which may give new insights into the organisation of the neurocircuitry regulating $\mathrm{GnRH}$ secretion. In the past decade, the rate of genetic discovery has dramatically accelerated, with defects in more than 10 genes now associated with $\mathrm{HH}$ [2]. Chromosome study in the cases with hypogonadism becomes essential from the clinical point of view. Bhagavath et al. [3] karyotyped $76 \mathrm{HH}$ patients and identified a sporadic male patient with complete $\mathrm{HH}$ and hyposmia who had a balanced chromosome translocation, reported as $46, \mathrm{XY}, \mathrm{t}(10 ; 12)$ (q26.3; 13.1$)$. Four cases reported of $(\mathrm{X} ; \mathrm{Y})$ translocations with a derivative $\mathrm{Y}$. All involved a portion of Xp22 and Xq28 translocated to Yq11, and all patients had normal stature, hypogonadism with hypoplastic male external genitalia or ambiguous genitalia, mental retardation, and various dysmorphic features [4,5]. In the present study, retrospective analysis of cytogenetic results in 64 cases revealed CAs in $18.8 \%$ of all cases with hypogonadism. The $15.6 \%$ of these 
karyotype anomalies were carriers of numerical aberrations, and 3.2\% were carriers of structural (Table 1).

The most frequent chromosome-related causes of $\mathrm{HH}$ are sex CAs. Among men with infertility, the most frequent cytogenetic findings are 47,XXY and 47,XXY/46,XY karyotypes. We also identified 9 males with $47, \mathrm{XXY}(\mathrm{KS})$ and variants, which accounted for the majority of the abnormalities, and the sex CA was the most common finding in male cases, accounting for about $3.4 \%$ (Table 1). Hypogonadism and gynecolnastia are the clinical manifestations of $\mathrm{KS}$ and its variants [6,7]. However, KS is the most common genetic cause of hypogonadism in men, and our study also reconfirmed this conclusion. The most common genotype is $47, \mathrm{XXY}$, but mosaicism $(46, \mathrm{XY} / 47, \mathrm{XXY})$ is also frequently seen. The patients have small firm testes and are generally infertile because of tubular damage. Testosterone concentrations in serum are low, but patients might present with concentrations at the lower end of the normal range and have a normal male phenotype. Some men with mosaicism have normal testicular size and spermato genesis at puberty, but germ cells are progressively lost over time [8]. The conclusion from all this information, phenotypic anomalies such as hypogonadism have been attributed to sex-chromosome mosaicism.

We report 2 cases (3.1\%) of a very rare variant form of KS $[47, \mathrm{Xi}(\mathrm{Xq}) \mathrm{Y}]$ that resulted in hypogonadism. Isochromosome $\mathrm{Xq}$ is a struc $\neg$ tural rearrangement frequently observed in Turner syndrome, but it is apparently rare in males [9]. It is suggested that the most probable origin of an $\mathrm{Xq}$ isochromosome is misdivision of the centromere or sister chromatid exchange of one X chromosome. Due to the limited number of cases, the prevalence of this KS is still unclear. Up to the present, 21 patients with $\mathrm{i}(\mathrm{Xq})$ have been reported in the literature, and reports on KS with an isochro $\neg$ mosome Xq have been discussed briefly in the literature; therefore, genetic counseling is difficult for such cases [10]. In general, all 47,Xi(Xq)Y patients have been reported to exhibit the main clinical features of KS, including reduced androgenization, small testes, azoospermia, gynecomastia, and ele $\neg$ vated FSH and LH levels. In general, all 47,Xi(Xq)Y patients have been reported to exhibit the main clinical features of KS, including reduced androgenization, small testes, azoospermia, gynecomastia, and ele $\neg$ vated FSH and LH levels. The only clinical difference between the 47,XXY and 47,Xi(Xq)Y KS patients is normalto-short stature in the latter. The height of the patient in our cases is compati $\neg$ ble with the previous reports.

However, X-chromosome deletions are usually sporadic, although familial cases have been reported. Deletions affecting the short arm of the $\mathrm{X}$ chromosome at band $\mathrm{p} 11.2$ result in ovarian failure in about half of women, and the other half experience menstrual irregularities. We also detected one female (1.6\%) with isochromosome Xq, and trisomy $\mathrm{Xq}$ resulting from an isochromosome $\mathrm{X}$ long arm abnormalities [46, $\mathrm{Xi}(\mathrm{Xq})$ ] (Table 1). The $46, \mathrm{Xi}(\mathrm{Xq})$ karyotype is found in $7 \%$ to $17 \%$ of individuals with TS [11,12]. Some reports [13-15] have indicated that patients with the $46, \mathrm{Xi}(\mathrm{Xq})$ karyotype have characteristics similar to those observed in classical TS. Patients with $\mathrm{i}(\mathrm{Xq})$ have similar characteristics to those with classical $45, \mathrm{X}$. However, patients with a deletion of Xp have short stature and congenital malformations Sybert and McCauley4 have reported the $46, \mathrm{Xi}(\mathrm{Xq})$ karyotype in $7 \%$ of patients with TS. The clinical anomalies in the $\mathrm{i}(\mathrm{Xq})$ type TS are cardiac disease, renal malformation, menstrual disorders, mental retardation, and edema. We observed no mental retardation in this case. We found that the isochromosome $\mathrm{i}(\mathrm{Xq})$ form of TS was generally milder than classic TS. A female with short stature and hypogonadism but without typical clinical findings of TS, should be evaluated for this chromosomal form.

Kallmann syndrome is a disease clinically characterized by the association of hypogonadotropic hypogonadism and anosmia or hyposmia. The hypogonadism is due to insufficient release of gonadotropin releasing hormone from the hypothalamus [16]. The KAL-1 gene structure for X-linked Kallmann syndrome revealed the presence of 14 exons spanning approximately $210 \mathrm{~kb}$ on Xp22.3 and shown to encode a protein sharing homology with molecules involved in neuronal migration and axonal pathfinding [17,18]. Kallmann syndrome rarely occurs as the result of a deletion involving only the KAL-1 gene $[19,20]$. Deletions of this gene are most frequently observed in males with a contiguous gene syndrome, including the loss of genes for ichthyosis, chondrodysplasia punctata, mental retardation and short stature in the distal short arm of the human X chromosome [21-25]. Thus, deletions of one short arm of the X chromosome in our case may be cause of hypogonadism. In the here reported the patient, cytogenetic analysis demonstrated a Robertsonian translocation between chromosomes 14 and 15 associated with hypogonadism.

\section{Conclusions}

The results suggest that CAs were a major cause of hypogonadism in humans. Therefore, cytogenetic analysis can be strongly recommended in hypogonadism individuals, and should be performed routinely in both the male and female with hypogonadism. Hypogonadism have been attributed to sex-chromosomes. These findings will could be used widely in the clinical genetics and will be an effective tool for genetic counseling and reproductive guide.

\section{References}

1. Ballabio A, Sebastio G, Carrozzo R, Parenti G, Piccirillo A, et al. (1989) Contiguous gene syndrome due to deletions in the distal short arm of the human X chromosome. Proc Natl Acad Sci USA 86: 10001-10005

2. Berengucr B, dE LA Cruz L, dE LA Plazar (1999) The role of lipoaspiration in defeminization of Klinefelter syndrome: a case report. Ann Plast Srug 43: 306-308.

3. Bhagavath B, Podolsky RH, Ozata M, Bolu E, Bick DP, et al. (2006) Clinical and molecular characterization of a large sample of patients with hypogonadotropic hypogonadism. Fertil Steril 85: 706-713.

4. Bick D, Curry CJR, McGill JR, Schorderet DF, Bux RC, et al. (1989) Male infant with ichthyosis, Kallmann syndrome, chondrodysplasia punctata, and a Xp chromosome deletion. Am J Med Gen 33: 100-107.

5. Catović A (2005) Cytogenetics findings at Turner Syndrome and their correlation with clinical findings. Bosn J Basic Med Sci 5: 54-58.

6. Demirhan O, Pazarbasi A, Tanriverdi N, Aridogan A, Karahan D (2009) The clinical effects of isochromosome Xq in Klinefelter syndrome: report of a case and review of literature. Genet Couns 20: 235-42.

7. Franco B, Guioli S, Pragliola A, Incerti B, Bardoni B, Tonlorenzi R (1991) A gene deleted in Kallmann syndrome shares homology with neural cell adhesion and axonal path-finding molecules. Nature 353: 529-36.

8. García CB, Robles CP, González Van (1991) Hypothyroidism and isochromosome X in Turner's syndrome [in Spanish]. An Esp Pediatr 34: 161-162.

9. Greenhall E and Vessey M (1990) The prevalence of subfertility: our view of the current confusion and a report of two new studies. Fertil Steril. 54: 978-983.

10. Hardelin JP, Levilliers J, Blanchard S, Carel JC, Leutenegger M, et al. (1993) Heterogeneity in the mutations responsible for X chromosomelinked Kallmann syndrome. Hum Mol Genet 2: 373-377. 
Citation: Demirhan O, Tanriverdi N, Süleymanova D, Cetinel N, Yasar Y (2015) The Frequency and Types of Chromosomal Aberrations in the Patients with Hypogonadism. Human Genet Embryol 5: 1000124. doi:10.4172/2161-0436.1000124

Page 4 of 4

11. Hsu YF (1994) Phenotype/karyotype correlations of Y chromosome aneuploidy with emphasis on structural aberrations in postnatally diagnosed cases. Am J Med Genet 53: 108-140.

12. Kim HG, Ahn JW, Kurth I, Ullmann R, Kim HT, et al. (2010) WDR11, WD protein that interacts with transcription factor EMX1, is mutated in idiopathic hypogonadotropic hypogonadism and Kallmann syndrome. Am J Hum Genet. 87: 465-479.

13. Legouis R, Hardelin JP, Levilliers J, Claverie JM, Compain S (1991) The candidate gene for the X-linked Kallmann syndrome encodes a protein related to adhesion molecules. Cell 67: 423-35.

14. Okada H, Fujioka H, Tatsumi N, Kanzaki M, Okuda Y, et. al. (1999) Klinefelter's syndrome in the male fertility. Clin Hum Repord.14: 946-52.

15. Quinton R, Duke VM, Zoisa PA, Platts AD, Valentine A, Kendall B. (1996) The neuroradiology of Kallmann's syndrome: a genotypic and phenotypic analysis. J Clin Endocrinol Metab 81: 3010-3017.

16. Reina C, Basso S, Perino A, Guraneri MO, Russo G.Brunelli V, Chiumello G (1994) Endocrinological problems in male adolescents. Pediatr Med Chir 18: 9-13.

17. Schinzel A, Lorda-Sanchez I, Binkert F, Carter NP, Bebb CE, et al. (1995) Kallmann syndrome in a boy with at $(1 ; 10)$ translocation detected by reverse chromosome painting. J Clin Genet 32: 957-961.
18. Saporta L, Yuksel A (1994) Androgenic status in patients with lepromatous leprosy. Br J Urol 74: 221-22.

19. Schmid W, Naef E, Murset G, Prader A (1974) Cytogenetic findings in 89 cases of Turner's syndrome with abnormal karyotypes. Humangenetik 24: 93-104.

20. Semple RK, Topaloglu AK (2010) The recent genetics of hypogonadotrophic hypogonadism - novel insights and new questions. Clinical Endocrinology 72: 427-435.

21. Sherins RJ, Howards SS. (1986) In: Walsh PC, ed. Male Infertility. Philadelphia: Campbell's Urology 640-97.

22. Sönmez S, Sönmez Y, Öztas S (1997) Isochromosome Xq in a girl having delayed puberty. Journal of Turgut Özal Medical Center 4: 109-111.

23. Sybert VP, McCauley E (2004) Turner's syndrome. N Engl J Med 351: 1227-1238.

24. Wikstrom AM, Dunkel L (2011) Klinefelter syndrome. Best Pract Res Clin Endocrinol Metab 25: 239-50.

25. Zinman B, Kabiawu SI, Moross T (1984) Endocrine, cytogenetic and psychometric features of patients with X-isochromosome 46, X, I (Xq) Turner's syndrome: A preliminary study in nine patients. Clin Invest Med 7: 135-141. 